\title{
End-of-life care conferences in Japanese nursing homes
}

\author{
Sho Nishiguchi ${ }^{1,2,3, *}$, Nagisa Sugaya ${ }^{2}$, Masahiko Inamori ${ }^{4}$ \\ ${ }^{1}$ Department of General Internal Medicine, Shonan Kamakura General Hospital, Kamakura, Japan; \\ ${ }^{2}$ Unit of Public Health and Preventive Medicine, Yokohama City University, Yokohama, Japan; \\ ${ }^{3}$ Department of Internal Medicine, Hayama Heart Center, Miura, Japan; \\ ${ }^{4}$ Department of Medical Education, Yokohama City University, Yokohama, Japan.
}

\begin{abstract}
Summary End-of-life (EOL) care conferences have an important role in promoting EOL care in nursing homes. However, the details of the conferences remain poorly understood. A Japanese prefecture-wide survey was conducted to investigate the factors involved in such conferences that contribute to an increase in the amount of EOL care. One hundred fiftythree nursing homes performed the conferences. The outcome was the amount of EOL care provided in nursing homes after adjusting for the facility beds in 2014. We investigated the factors of staff experience with EOL care, frequency of the conferences, years the conferences were conducted, review conferences after EOL care, and professional participants in the conferences. The multivariate analysis revealed significant associations between EOL care in nursing homes and nurses' experience with EOL care (adjusted $\beta$ coefficient $2.9,95 \%$ confidence interval (CI) $0.52 \sim 5.22, p=0.017$ ), more than 5 years of continuous conferences (adjusted $\beta$ coefficient 3.8, 95\% CI $0.46 \sim 7.05, p=0.026$ ), and family participation (adjusted $\beta$ coefficient $-4.0,95 \% \mathrm{CI}-7.5 \sim-0.48, p=0.026$ ). In conclusion, the continuation of conferences and enrollment of the nurse with experience in EOL care may promote EOL care in nursing homes, while family enrollment in conferences may decrease EOL care in nursing homes. EOL care conferences in nursing homes should be continuously performed by staff, with an experienced nurse undertaking the task of information sharing before discussing EOL care with the patients' families.
\end{abstract}

Keywords: End-of-life care conferences, end-of-life care, interdisciplinary care, interprofessional collaboration, nursing home, Japan

\section{Introduction}

In aging societies, nursing homes that provide 24-hour functional support to frail elderly residents (1), who require assistance due to diminished capacity, play an important role in end-of-life (EOL) care. In Japan, EOL care in nursing homes has gradually increased over the past decade (2-4). However, approximately 30\% of facilities continue to transfer residents to hospitals for EOL care $(2,4)$. In the remaining $70 \%$ of facilities, approximately $40 \%$ of the residents receive EOL care and ultimately die in hospitals rather than in nursing

\footnotetext{
*Address correspondence to:

Dr. Sho Nishiguchi, Department of General Internal Medicine, Shonan Kamakura General Hospital, Okamoto 1370-1, Kamakura City, Kanagawa Prefecture, 247-8533, Japan.

E-mail: sanazen@hotmaill.co.jp
}

homes $(2,4)$. Thus, residents may be transferred to hospitals against their wishes for EOL care.

Multidisciplinary care is a requirement of EOL care in nursing homes. However, providing EOL care overnight is challenging. Nurses in nearly all nursing homes work on-call shifts during the evenings (5). Professional caregivers in nursing homes usually perform EOL care without assistance during the nighttime (6). Thus, the professional caregiver's role may be practically the most important. Professional caregivers who do not have sufficient experience with EOL care have fears about EOL care (7). Thus, multidisciplinary care is essential to prevent unnecessary anxiety in nighttime professional caregivers who are inexperienced with EOL care.

EOL care conferences were introduced in the Japanese guidelines for EOL care in nursing homes (8), which state that such conferences promote 
communication among multidisciplinary professionals through the sharing of information regarding the residents' condition and the wishes of the residents or their families regarding EOL care. Specifically, these conferences provide the opportunity to discuss the goals of EOL care, care planning, and the role of each discipline in EOL care for the resident. Participants in the EOL care conference include the physician, nurse, professional caregiver, care manager, social worker, resident (if possible), and resident's family.

In our previous study, we revealed that EOL care conferences are related to increased EOL care in nursing homes (2). However, the importance of EOL care conferences remains poorly understood worldwide. Studies investigating the details of EOL care conferences are limited. Therefore, we conducted this study to clarify the conference factors associated with increased EOL care among nursing homes performing EOL care conferences.

\section{Materials and Methods}

\subsection{Design, setting and participants}

We analyzed cross-sectional data acquired in 2014 from our previous longitudinal survey (2). The survey was conducted using a questionnaire based on our pilot study, which included face-to-face interviews with nursing home staff. After sending several requests by fax or phone to non-responsive nursing homes, all questionnaires were returned to our office by May 2016. Among the responding nursing homes, the facilities with EOL care conferences were enrolled in this study. The targeted nursing homes included all 378 facilities in Kanagawa Prefecture, Japan (Figure 1). Kanagawa Prefecture is a city adjacent to Tokyo with a population of 9.1 million; it had an elderly population rate of $22.5 \%$ in 2014 . Kanagawa Prefecture is projected to experience the highest increase in the elderly population rate over the next 20 years. The present study focused on facilities holding EOL care conferences.

\subsection{Measurements}

The outcome was the amount of EOL care provided in nursing homes, which was assessed in terms of the number of residents dying in nursing homes per 100 beds in the facilities in 2014. The independent factors included the nurses' experience with EOL care; the care managers' experience with EOL care; the professional caregivers' experience with EOL care; the frequency of EOL care conferences; the number of years the EOL care conferences were conducted; review conferences after providing EOL care; and the professionals among the participants, which included the doctor, facility director, nurse, care manager, professional caregiver, nutritionist, social worker, and family. The

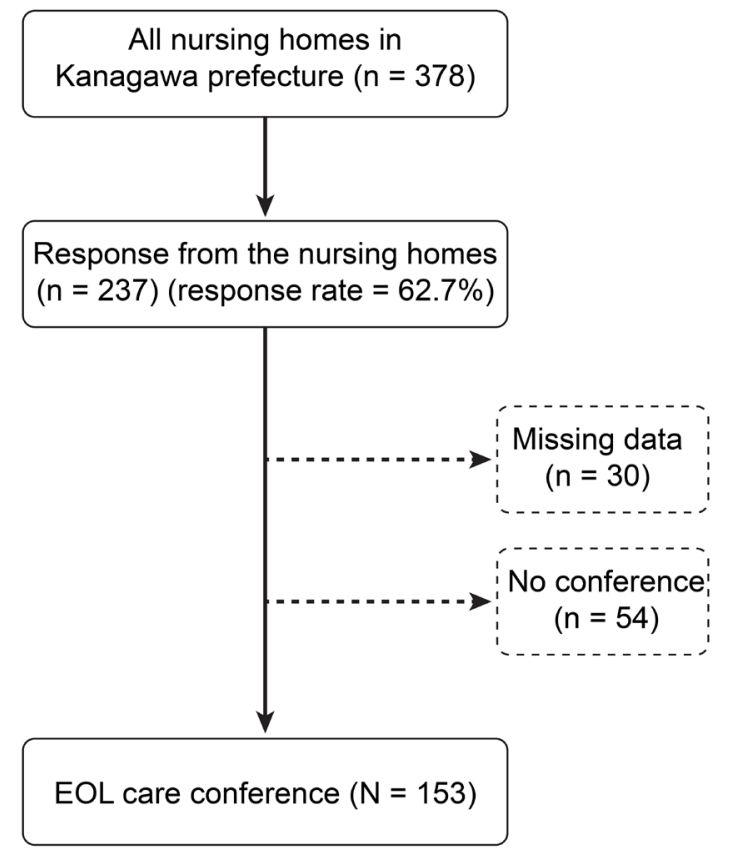

Figure 1. Flow diagram of nursing homes for study inclusion.

nurses, care managers, and professional caregivers are the main participants in the EOL care conferences. Their experience with EOL care is important in the conference. Thus, we included their experience with EOL care as the content of the conference. In the questionnaire, we assessed experience with EOL care using the following three categories: no experience, from one to four experiences, and five or more experiences. Review conferences after EOL care were defined as multidisciplinary professionals discussing and reviewing EOL care after the resident's death.

\subsection{Ethical considerations}

The study was approved by the institutional review boards of the university (No. A140522015, approved on 24 July 2014). The consent of the nursing home facilities was implied and documented by the return of the questionnaires.

\subsection{Statistical analysis}

A univariate analysis was performed using $t$-tests for two groups and one-way analysis of variance (ANOVAs) for three or more groups. A multivariate analysis was conducted using a linear regression model. In the multivariate analysis, the independent factors included whether the participants had more than 5 experiences with EOL care, whether the conferences were held weekly, and whether the conferences continued for more than 5 years. All analyses in this study were performed using International Business Machines Corporation (IBM) SPSS Statistics version 
J21 (IBM, Tokyo, Japan). A $p$-value $<0.05$ was considered statistically significant in all analyses.

\section{Results}

Among all 378 nursing home facilities in the prefecture, 237 facilities $(62.7 \%)$ responded after a reminder by fax or phone, and the remaining 141 nursing homes $(37.3 \%)$ did not respond. Data were missing from 30 nursing homes. Among the available 207 facilities, 54 facilities held no EOL care conferences (Figure 1). Ultimately, 153 nursing homes (40.5\%) were included in the present study, representing $73.9 \%$ of responding nursing homes performing EOL care conferences.

Of these 153 facilities, 121 facilities (79.1\%) were established before 2005 . The mean elderly population rate in the area in which these facilities were located was $23.7 \%$ (standard deviation (SD): $3.2 \%$ ), and the mean number of hospital beds per 10 million inhabitants in the facilities' regions was 806.8 (SD: 216.2). Sixtytwo facilities $(40.8 \%)$ used unit care, which generally requires all single rooms with a common living and dining room per 10 beds in a facility. Eleven (7.2\%) doctors worked full time on site, and 69 doctors (45.1\%) were on call for emergency care during the nighttime. The mean number of nurses was 6.6 (SD: 2.6), the mean number of full-time nurses on site was 3.4 (SD: $1.5)$, and 128 facilities (84.8\%) adopted a nurse oncall system during the nighttime. The number of fulltime nurses was few, and there was no nurse during the nighttime in almost all the nursing homes. If nurses' opinions are needed during the nighttime, professional caregivers or other staff will call on-call nurses in almost all facilities. Regarding the basic policies for EOL care, 122 (79.7\%) facilities provided EOL care in the nursing home, $15(9.8 \%)$ facilities transferred the residents to a hospital, and $16(10.5 \%)$ facilities had no explicit policy. In total, 119 (77.8\%) nursing homes adopted an EOL care bonus, and 14 facilities were preparing for this bonus in the near future.

The results of the univariate analysis of the EOL care conference factors associated with the amount of EOL care provided in nursing homes are shown in Table 1. Among the factors involving experience with EOL care, the experience of the nurses $(p=0.020)$ and professional caregivers $(p=0.020)$ was significantly associated with the amount of EOL care provided in the nursing homes. No significant results were detected in the factors involving the content of the conference. Among the factors involving the participants in the conference, family enrollment $(p=0.020)$ was significantly associated with decreased EOL care in the nursing homes.

In the multivariate analysis, the nurses' experience with EOL care (adjusted $\beta$ coefficient 2.9, 95\% confidence interval (CI), $0.52 \sim 5.22 ; p=0.017$ ), continuation of conferences for more than 5 years
Table 1. Univariate analysis of factors associated with EOL care in nursing homes $(n=153)$

\begin{tabular}{|c|c|c|c|}
\hline Items & $\begin{array}{l}\text { Facility } \\
\text { number }\end{array}$ & $\begin{array}{c}\text { Amount of EOL } \\
\text { care in nursing } \\
\text { homes }\end{array}$ & $p$-value \\
\hline \multicolumn{4}{|c|}{ Experience with EOL care } \\
\hline \multicolumn{4}{|l|}{ Nurse } \\
\hline 0 & $17(11.1)$ & $9.3 \pm 8.4$ & \multirow[t]{3}{*}{$0.020 *$} \\
\hline 1-4 times & $12(7.8)$ & $7.2 \pm 5.6$ & \\
\hline$\geq 5$ times & $119(77.8)$ & $14.5 \pm 9.6$ & \\
\hline \multicolumn{4}{|l|}{ Care manager } \\
\hline 0 & $17(11.1)$ & $14.0 \pm 13.8$ & \multirow[t]{3}{*}{0.727} \\
\hline 1-4 times & $29(19.0)$ & $12.0 \pm 10.1$ & \\
\hline$\geq 5$ times & $103(67.3)$ & $13.5 \pm 8.5$ & \\
\hline \multicolumn{4}{|l|}{ Professional caregiver } \\
\hline 0 & $17(11.1)$ & $17.2 \pm 15.3$ & \multirow[t]{3}{*}{$0.020^{*}$} \\
\hline $1-4$ times & $37(24.2)$ & $9.6 \pm 7.5$ & \\
\hline$\geq 5$ times & $94(61.4)$ & $13.7 \pm 8.4$ & \\
\hline \multicolumn{4}{|l|}{ Contents of conference } \\
\hline Frequency & & & \\
\hline Every several days & $3(2.6)$ & $6.2 \pm 4.2$ & \multirow{5}{*}{0.516} \\
\hline Every week & $35(22.9)$ & $11.7 \pm 8.7$ & \\
\hline Every two weeks & $6(3.9)$ & $10.0 \pm 8.3$ & \\
\hline Every month & $4(2.6)$ & $14.0 \pm 9.7$ & \\
\hline On a timely basis & $97(63.4)$ & $15.7 \pm 11.7$ & \\
\hline \multicolumn{4}{|c|}{$\begin{array}{l}\text { Years from initiation of } \\
\text { the conference }\end{array}$} \\
\hline$<$ 5years & $70(45.8)$ & $11.2 \pm 8.3$ & \multirow[t]{2}{*}{0.069} \\
\hline$\geq$ 5years & $57(37.3)$ & $14.0 \pm 8.2$ & \\
\hline \multicolumn{4}{|c|}{ Review conference after } \\
\hline EOL care & & & \\
\hline Yes & $116(75.8)$ & $12.9 \pm 8.5$ & \multirow[t]{2}{*}{0.290} \\
\hline No & $34(22.2)$ & $14.9 \pm 12.1$ & \\
\hline \multicolumn{4}{|l|}{ Participant } \\
\hline \multicolumn{4}{|l|}{ Doctor } \\
\hline Yes & $31(20.3)$ & $13.1 \pm 12.1$ & \multirow[t]{2}{*}{0.985} \\
\hline No & $116(75.8)$ & $13.2 \pm 8.6$ & \\
\hline \multicolumn{4}{|l|}{ Facility director } \\
\hline Yes & $51(33.3)$ & $13.3 \pm 11.8$ & \multirow[t]{2}{*}{0.952} \\
\hline No & $96(62.7)$ & $13.1 \pm 7.9$ & \\
\hline \multicolumn{4}{|l|}{ Nurse } \\
\hline Yes & $145(94.8)$ & $13.2 \pm 9.4$ & \multirow[t]{2}{*}{0.780} \\
\hline No & $2(1.3)$ & $11.3 \pm 3.7$ & \\
\hline \multicolumn{4}{|l|}{ Care manager } \\
\hline Yes & $145(94.8)$ & $13.2 \pm 9.4$ & 0.580 \\
\hline No & $3(2.0)$ & 8.0 & \\
\hline Professional caregive & & & \\
\hline Yes & $145(94.8)$ & $12.9 \pm 8.5$ & 0.536 \\
\hline No & $3(2.0)$ & $25.3 \pm 29.0$ & \\
\hline Nutritionist & & & \\
\hline Yes & $131(85.6)$ & $13.3 \pm 9.8$ & 0.454 \\
\hline No & $16(10.5)$ & $12.1 \pm 5.5$ & \\
\hline Social worker & & & \\
\hline Yes & $32(20.9)$ & $13.7 \pm 12.4$ & 0.760 \\
\hline No & $115(75.2)$ & $13.0 \pm 8.4$ & \\
\hline Family & & & \\
\hline Yes & $80(52.3)$ & $11.5 \pm 9.8$ & $0.021 *$ \\
\hline No & $67(43.8)$ & $15.2 \pm 8.5$ & \\
\hline
\end{tabular}

EOL: end-of-life, Based on Student's $t$-test or one-way analysis of variance (ANOVA), where appropriate, ${ }^{*} p<0.05$

(adjusted $\beta$ coefficient 3.8, 95\% CI $0.46 \sim 7.05, p=$ 0.026 ), and family participation (adjusted $\beta$ coefficient $-4.0,95 \%$ CI $-7.50 \sim-0.48, p=0.026$ ) were significantly associated with the number of residents dying in the nursing homes (Table 2). 
Table 2. Results of the multivariate analysis $(n=153)$

\begin{tabular}{lcrl}
\hline Items & $\beta$ & $95 \% \mathrm{CI}$ & $p$-value \\
\hline Experience with EOL care $\geq 5$ times & & & \\
$\quad$ Nurse & 2.9 & $0.52 \sim 5.22$ & $0.017^{*}$ \\
$\quad$ Care manager & 1.2 & $-1.26 \sim 3.73$ & 0.327 \\
$\quad$ Professional caregiver & -0.5 & $-2.94 \sim 1.95$ & 0.689 \\
Contents of the conference & & & \\
$\quad$ Every week & 2.8 & $-0.74 \sim 6.31$ & 0.120 \\
$\quad$ 5years & 3.8 & $0.46 \sim 7.05$ & $0.026^{*}$ \\
$\quad$ Review conference after dying & -0.3 & $-4.34 \sim 3.69$ & 0.872 \\
Participant & & & \\
$\quad$ Doctor & 1.5 & $-3.39 \sim 3.73$ & 0.541 \\
Facility director & 1.5 & $-2.30 \sim 5.24$ & 0.441 \\
$\quad$ Nurse & -3.3 & $-16.36 \sim 9.68$ & 0.612 \\
Care manager & - & - & - \\
$\quad$ Professional caregiver & - & - & - \\
$\quad$ Nutritionist & -2.4 & $-8.40 \sim 3.65$ & 0.436 \\
$\quad$ Social worker & 1.4 & $-2.51 \sim 5.24$ & 0.484 \\
Family & -4.0 & $-7.50 \sim-0.48$ & $0.026^{*}$ \\
\hline
\end{tabular}

EOL: end-of-life, CI: confidence interval. Based on multiple linear regression analysis, ${ }^{*} p<0.05$. The factors of care manager and caregiver were excluded from the analysis, because almost all of those participate in an EOL care conference.

\section{Discussion}

In the present cross-sectional study performing a prefecture survey in Japan, nurses' experience with EOL care, the continuation of conferences for more than 5 years, and the lack of family participation were associated with increased EOL care in nursing homes among facilities performing EOL care conferences.

In a previous small sample study, nurses' experience with EOL care had a positive effect on their tenure and professional efficacy (7). Moreover, in our previous study, we showed that employing nurses with more than 5 experiences with EOL care was associated with increased EOL care in nursing homes (2), which is consistent with the results of the present study involving facilities performing EOL care conferences. The association between the nurses' experiences and the increased EOL care in the nursing homes among facilities performing EOL care conferences may be associated with the nurses' leadership $(9,10)$. The role of nurses is essential for the implementation of EOL care because nurses are the only medical providers in most nursing homes $(2,5)$.

To date, no studies have reported a relationship between increased EOL care in nursing homes and the continuation of EOL care conferences for more than 5 years. This result regarding the continuation of EOL care conference for more than 5 years is logical in terms of increased EOL care in nursing homes because improvement in EOL care in nursing homes requires time after the initiation of EOL care conferences.

In the context of palliative care in an intensive care unit, family participation in conferences regarding EOL care promotes communication between families and the doctor, satisfaction and perceived quality of dying for

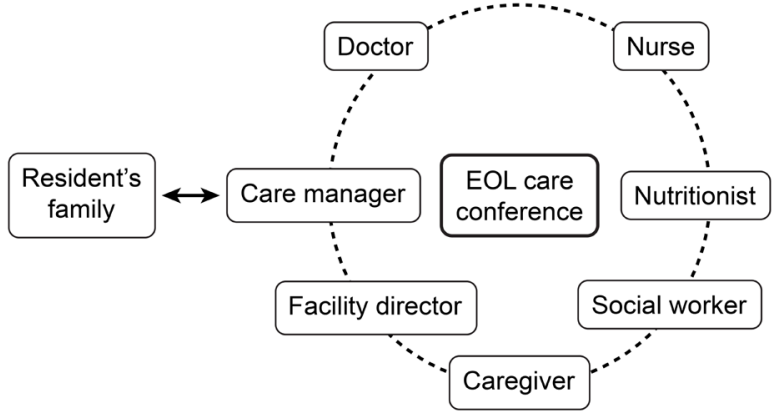

Figure 2. Hypothesis of the ideal relationship between nursing home staff and residents' family.

families, and communication of information to families (11-16). In the context of long-term palliative care, family participation in a conference regarding EOL care affects communication and understanding between the family and the facility's staff, reducing stress, anxiety and undesirable hospitalization (17). However, no study has investigated how family participation may interfere with EOL care in nursing homes. One explanation for the association between family participation and decreased EOL care in nursing homes may be the difficulty of reaching an agreement without information sharing and discussion among professional staff in facilities. In our interviews with the care managers of these facilities, nursing homes that provided more EOL care adopted the model shown in Figure 2, in which the care manager, as a representative of the facility, has the opportunity to speak with the resident's family after information sharing with the resident receiving EOL care and discussion in an EOL care conference. This model can contribute to smooth communication between the facility's staff and the residents' families regarding EOL care. Therefore, EOL care conferences may play an important role in sharing the residents' condition and discussing EOL care.

Although interprofessional collaboration and communication in nursing homes have recently attracted attention (18-21), to the best of our knowledge, no study to date has investigated the details of the conferences regarding EOL care in nursing homes. Compared with that of a general survey study, the response rate in our study was higher due to collaboration with the local government's directors (Figure 1). Thus, the study's internal validity is high.

The present study includes several limitations. First, there was a relatively large amount of missing data regarding EOL care conferences (Figure 1). Second, a study performed in a single prefecture surrounding a Japanese metropolis may have selection bias. Third, since the study used a cross-sectional design, the results of the present study are unable to address causal relationships.

In our previous study, we reported that EOL care conferences were related to increased EOL care in nursing homes (2). The present study additionally investigated how EOL care conferences are performed 
to best achieve EOL care in nursing homes. However, as previously mentioned, a retrospective study design cannot demonstrate the causal relationship by which EOL care conferences promote EOL care in nursing homes. Therefore, a multifacility prospective study based on our results is needed in the near future for an aging society.

\section{Conclusions}

Nurses' experience with EOL care and the continuation of EOL care conferences for more than 5 years may promote EOL care in nursing homes, while family participation in the conferences may interfere with EOL care in nursing homes. EOL care conferences in nursing homes are recommended to be continuously performed by the facility's staff with an experienced nurse undertaking the task of information sharing, before discussing EOL care with the families.

\section{Acknowledgements}

The authors thank the Uehiro Foundation on Ethics and Education [grant number A-046, 2015]. Funding was also provided in part by the Kanagawa Public Health Association [2014] for the pilot survey. The authors thank the directors of the Health and Welfare Departments in Yokohama City, Kawasaki City, Yokosuka City, and Sagamihara City, Kanagawa Prefecture, who assisted with this study. The authors also thank Kanda Hideyuki MD, PhD (Shimane University, Japan) and Takahashi Kenzo MD, PhD, MHS (Teikyo University, Japan) for their thoughtful comments on the study.

\section{References}

1. Sanford A. Orrell M, Tolson D, et al. An international definition for "nursing home". J Am Med Dir Assoc. 2015; 16:181-184.

2. Nishiguchi S, Sugaya N, Sakamaki K, Mizushima S. Endof-life care bonus promoting end-of-life care in nursing homes: An 11-year retrospective longitudinal prefecturewide study in Japan. Biosci Trends. 2017; 11:54-61.

3. Ikegami N, Ikezaki S. Nursing homes and end-of-life care in Japan. J Am Med Dir Assoc. 2013; 14:718-723.

4. Takezako Y, Ishikawa S, Kajii E. Advance directives in Japanese nursing homes. J Pain Symptom Manage. 2013; 45:63-70 e7.

5. Ikegami N, Ikezaki S. Japan's policy of promoting end-oflife care in nursing homes: Impact on facility and resident characteristics associated with the site of death. Health policy. 2012; 105:303-311.

6. Hashimoto M, Ono S. Factors Hindering End-of-life Care at Special Nursing Homes for the Elderly (special nursing homes); An Attitude Survey Involving the Staff of Special Elderly Nursing Homes, Which had Difficulty Promoting "End-of-life care". Shi-no-rinsho. 2014; 37:142-147. (in Japanese)

7. Abe K, Ohashi A. Positive effects of experience in terminal care on nursing home staff in Japan. Am J Hosp
Palliat Care. 2011;28:389-392.

8. Mitsubishi Research Institute. Tokubetsu yougo roujin homu niokeru shisetsu sarvice no shitsu kakuho ni kansuru kentou houkokusyo. 2007; 6-14. (in Japanese)

9. Fahlberg B, Buck H. Nurses: We can lead and transform palliative care. Nursing. 2017; 47:15-17.

10. D'Antonio J. End-of-life nursing care and education: Endof-life nursing education: Past and present. J Christ Nurs. 2017; 34:34-38.

11. Machare Delgado E, Callahan A, Paganelli G, Reville B, Parks SM, Marik PE. Multidisciplinary family meetings in the ICU facilitate end-of-life decision making. Am J Hosp Palliat Care. 2009; 26:295-302.

12. Azoulay E. The end-of-life family conference: Communication empowers. Am J Respir Crit Care Med. 2005; 171:803-804.

13. Azoulay E, Pochard F, Chevret S, Lemaire F, Mokhtari M, Le Gall JR, Dhainaut JF, Schlemmer B. Meeting the needs of intensive care unit patient families: A multicenter study. Am J Respir Crit Care Med. 2001; 163:135-139.

14. Azoulay E, Pochard F, Chevret S, et al. Impact of a family information leaflet on effectiveness of information provided to family members of intensive care unit patients: A multicenter, prospective, randomized, controlled trial. Am J Respir Crit Care Med. 2002; 165:438-442.

15. Lilly CM, De Meo DL, Sonna LA, Haley KJ, Massaro AF, Wallace RF, Cody S. An intensive communication intervention for the critically ill. Am J Med. 2000; 109:469-475.

16. Curtis JR, Patrick DL, Shannon SE, Treece PD, Engelberg RA, Rubenfeld GD. The family conference as a focus to improve communication about end-of-life care in the intensive care unit: Opportunities for improvement. Crit Care Med. 2001; 29(2 Suppl):N26-33.

17. Parker D, Clifton K, Tuckett A, Walker H, Reymond E, Prior T, McAnelly K, Jenkin P, Israel F, Greeve K, Glaetzer K. Palliative care case conferences in long-term care: Views of family members. Int J Older People Nurs. 2016; 11:140-148.

18. Mueller CA, Tetzlaff B, Theile G, Fleischmann N, Cavazzini C, Geister C, Scherer M, Weyerer S, van den Bussche H, Hummers-Pradier E. Interprofessional collaboration and communication in nursing homes: A qualitative exploration of problems in medical care for nursing home residents - study protocol. J Adv Nurs. 2015; 71:451-457.

19. Fleischmann N, Geister C, Hoell A, Hummers-Pradier E, Mueller CA. Interprofessional collaboration in nursing homes (interprof): A grounded theory study of nurse experiences of general practitioner visits. Applied Nursing Research. 2017; 35:118-125.

20. Fleischmann N, Tetzlaff B, Werle J, Fleischmann N, Cavazzini C, Geister C, Scherer M, Weyerer S, van den Bussche H, Hummers-Pradier E. Interprofessional collaboration in nursing homes (interprof): A grounded theory study of general practitioner experiences and strategies to perform nursing home visits. BMC Fam Pract. 2016; 17:123.

21. Sheppard KD, Ford CR, Sawyer P, Foley KT, Harada CN, Brown CJ, Ritchie CS. The interprofessional clinical experience: Interprofessional education in the nursing home. J Interprof Care. 2015; 29:170-172.

(Received January 14, 2019; Revised February 19, 2019; Accepted February 25, 2019) 